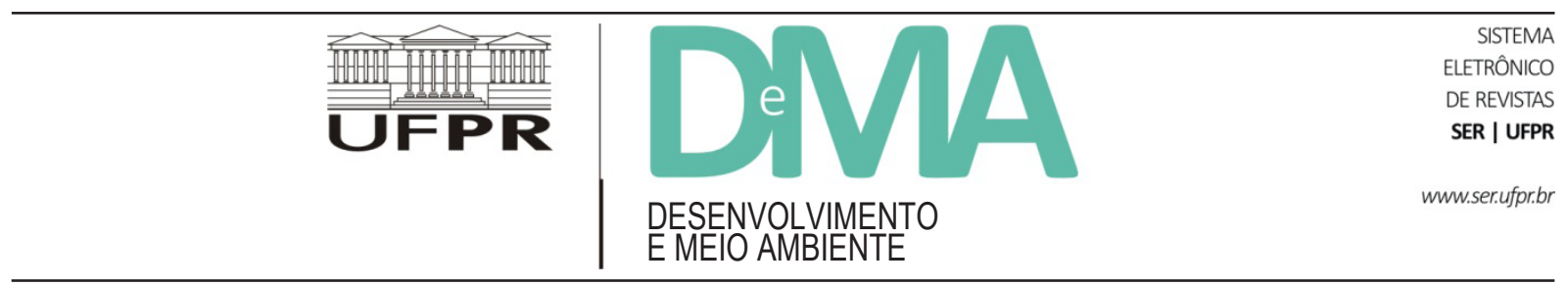

\title{
Participação pública no processo de avaliação de impacto ambiental no Estado do Espírito Santo
}

\section{Public Participation in the Environmental Impact Assessment Process in the State of Espírito Santo}

\author{
Giulianna Calmon FARIA ${ }^{1 *}$, Fátima Maria SILVA ${ }^{1}$ \\ ${ }^{1}$ Universidade Federal do Espírito Santo (UFES), Vitória, ES, Brasil. \\ *E-mail de contato: giuliannacalmon@hotmail.com
}

Artigo recebido em 29 de julho de 2017, versão final aceita em 14 de novembro de 2017.

RESUMO: Sob as afirmações de deixar o processo de Avaliação de Impacto Ambiental (AIA) mais ágil e menos burocrático, alguns países têm adotado medidas opostas à democratização da gestão ambiental, reduzindo o envolvimento do público e adotando mudanças controversas, como eliminar a participação pública dos processos de avaliação de classes especiais de projetos. A importância atribuída à participação do público, na prática, é ecoada na literatura científica não apenas como um princípio em si, mas parece haver um consenso generalizado de que esta participação também é fundamental para uma avaliação ambiental efetiva. Esse artigo tem como objetivo identificar as formas de participação pública no processo de AIA de projetos no Estado do Espírito Santo. Para tanto, foi adotada a metodologia de pesquisa documental no âmbito do Instituto Estadual de Meio Ambiente, nos processos de licenciamento ambiental de empreendimentos que apresentaram Estudo de Impacto Ambiental, desde a publicação, em janeiro de 2007, do Decreto $n^{\circ}$ 1.777-R, que dispõe sobre o Sistema de Licenciamento e Controle de Atividades Poluidoras ou Degradadoras do Meio Ambiente/Silcap, que atualmente constitui o principal instrumento utilizado pelo órgão ambiental estadual para as atividades relacionadas ao licenciamento ambiental. A pesquisa incluiu todos os documentos disponíveis em meio físico e digital referentes à participação pública em 44 processos de licenciamento ambiental, entre janeiro de 2007 e maio de 2016.

Palavras-chave: participação pública; avaliação de impacto ambiental; estudo de impacto ambiental; licenciamento ambiental.

ABSTRACT: Under the assertions of making the EIA process more agile and less bureaucratic, some countries have taken opposing measures to democratize environmental management by reducing public involvement by adopting controversial changes such as eliminating the public participation of special classes of projects. The importance attached to public participation in practice is echoed in the scientific literature not only as a principle in itself, but there seems to be a general agreement that public participation is also central to an effective environmental assessment. This article aims to identify the forms of public participation in the EIA process of projects in 
the State of Espírito Santo. In order to do so, the documentary research methodology was adopted within the framework of the State Environmental Institute, in the environmental licensing processes of projects that presented an Environmental Impact Study. Decree No. 1,777-R, which provides for the System for the Licensing and Control of Pollution and Environmental Degradation Activities / SILCAP, which is currently the main instrument used by the state environmental activities related to environmental licensing. The survey included all the physical and digital documents available for public participation in 44 environmental licensing processes between January 2007 and May 2016.

Keywords: public participation; environmental impact assessment; environmental impact statement; environmental licensing.

\section{Introdução}

Ao longo dos anos, a participação pública tem sido cada vez mais institucionalizada na tomada de decisões ambientais nos níveis local, regional e internacional (Li et al., 2012). A possibilidade de chegada de grandes projetos ${ }^{1}$ acaba gerando expectativas na sociedade e em autoridades estaduais e municipais com a promessa de benefícios, como geração de empregos e de tributos. Porém, projetos com potencial poluidor do meio ambiente podem trazer também malefícios, como piora da qualidade atmosférica, contaminação dos recursos hídricos e até mesmo prejuízos aos recursos naturais (Sánchez, 2013).

Assim, o fortalecimento e talvez a ampliação dos canais de discussão onde tomadores de decisão são postos a ouvir os anseios, as aspirações e os receios da comunidade no processo de licenciamento ambiental oferecem oportunidade de crescimento a todos os atores envolvidos no processo, capacitando os participantes a desenvolverem melhor seus papéis na sociedade. Partindo da utilização da avaliação de impacto ambiental como instrumento primordial para a tomada de decisão no processo de licenciamento ambiental de grandes projetos, este artigo traz uma abordagem acerca da participação pública nesse contexto e tem como principal objetivo identificar as formas de participação pública no processo de Avaliação de Impacto Ambiental no Estado do Espírito Santo, sua prática e frequência (Glucker et al., 2013).

\section{Avaliação de Impacto Ambiental no Espírito Santo}

A Avaliação de Impacto Ambiental (AIA) é uma ferramenta que tem sido bem-sucedida, considerando efeitos sociais, econômicos e ambientais na avaliação dos principais projetos de desenvolvimento. Considerada um instrumento inovador, após o início de sua aplicação foram encontrados inúmeros problemas, inclusive na sua relação com a ciência (Cashmore, 2004). Agora, em sua quarta década de aplicação, a AIA evoluiu para um instrumento essencial de gestão ambiental e de tomada de decisão que é utilizado em todo o mundo. Tendo crescido constantemente o seu uso, desde as aplicações precoces na década de 1970, houve o reconhecimento da AIA na Cimeira da Terra no Rio de Janeiro, em 1992, sendo aplicada amplamente em todo o mundo. Hoje, a AIA é usada em mais de 100 países e muitos

\footnotetext{
${ }^{1}$ São projetos com potencial poluidor geralmente industriais, de infraestrutura, de mineração, relacionados, no Brasil, na Resolução Conama $\mathrm{n}^{\circ}$ 01/1986 (Conselho Nacional do Meio Ambiente, 1986).
} 
outros tipos de avaliação de impacto têm evoluído (Bond et al., 2014).

Pode-se afirmar que a primeira institucionalização da AIA no Estado do Espírito Santo foi a partir da Lei Estadual no 3.582/83, que, em seu Art. $7^{\circ}$, determina que a localização, a instalação, a operação e a ampliação de fontes de poluição ficam sujeitas à autorização da Secretaria de Estado para Assuntos do Meio Ambiente (SEAMA), mediante licenças apropriadas, após o exame do impacto ambiental e de acordo com o respectivo relatório conclusivo (Espírito Santo, 1983, p. 2).

Semelhante à legislação federal, a Constituição do Estado do Espírito Santo determina que para a localização, a instalação, a operação e a ampliação de obra ou atividade potencialmente causadora de significativa degradação do meio ambiente, será exigido relatório de impacto ambiental, na forma da lei, que assegurará a participação da comunidade em todas as fases de sua discussão (Espírito Santo, 1989, p. 96).

No ano de 1998, o Estado do Espírito Santo publicou no Diário Oficial do Estado o Sistema de Licenciamento de Atividades Poluidoras (SLAP), por meio do Decreto Estadual no 4.344-N (Espírito Santo, 1998). O SLAP cita como instrumento do licenciamento o Estudo de Impacto Ambiental e seu respectivo Relatório de Impacto Ambiental, além da Declaração Ambiental, entre outros listados em seu artigo 11. O decreto delega ao órgão competente a possibilidade de se exigir Estudo de Impacto Ambiental (EIA) sempre que necessário e baseado em parecer técnico fundamentado, além dos casos previstos na legislação vigente.

Em seu Art. 35, o Decreto Estadual No 4.344-N determina que o parecer técnico resultante da análise do EIA, emitido pela Seama, deverá ser apreciado pelo Conselho Estadual de Meio Ambiente, em prazo máximo de trinta dias, após formalmente convocado por seu Presidente (Espírito Santo, 1998, p. 12).

A partir da Constituição Estadual do Espírito Santo, o licenciamento só voltou a ser abordado em janeiro de 2007, quando foi instituído o Sistema de Licenciamento Ambiental e Controle das Atividades Poluidoras e Degradadoras do Meio Ambiente (Silcap), por meio do Decreto $n^{\circ} 1.777-R$. Este constitui o principal instrumento utilizado pelo órgão ambiental estadual para as atividades relacionadas ao licenciamento ambiental (Espírito Santo, 2007). Em dezembro de 2016, o Silcap teve sua atualização publicada no Diário Oficial do Estado do Espírito Santo, no dia 8 de dezembro, passando a vigorar o Decreto no 4039-R de 07 de dezembro de 2016 (Espírito Santo, 2016). Porém, vale ressaltar que toda pesquisa foi realizada durante a vigência do Decreto n ${ }^{\circ}$ 1.777-R (Espírito Santo, 2007).

Em seu artigo 22, o Silcap estabelece que o órgão competente determinará, com base em parecer técnico fundamentado, a realização da Avaliação Ambiental, o que posteriormente, no mesmo decreto, é denominado de Estudo de Impacto Ambiental (Espírito Santo, 2007).

No Estado do Espírito Santo existem dois órgãos licenciadores no âmbito estadual, que são o Instituto Estadual de Meio Ambiente (IEMA) e o Instituto de Defesa Agropecuária e Florestal do Espírito Santo (IDAF). Entre as poucas atividades ${ }^{2}$ licenciadas pelo IDAF, somente o plantio florestal ou agrícola acima de 100 hectares tem a exigência de apresentação de EIA. Já o IEMA realiza o licenciamento de quase todas as atividades passíveis de

\footnotetext{
${ }^{2}$ Poucas atividades em relação ao IEMA no licenciamento de âmbito estadual.
} 
licenciamento, inclusive as industriais, portuárias e de infraestrutura em geral (Conselho Nacional do Meio Ambiente, 1986; Espírito Santo, 1989; 2007).

Percebe-se que a legislação ambiental do Estado do Espírito Santo tem sofrido alterações com períodos de aproximadamente 10 anos de intervalo entre as atualizações, o que pode ser considerado satisfatório quando olhado à luz da legislação federal, cujas normas relativas à AIA datam do final da década de 80 e início da década de 90.

\section{Participação pública na AIA}

O termo participação pode ser encontrado na bibliografia como participação cidadã, participação pública e algumas vezes como participação popular. Porém, pode-se afirmar que, mesmo existindo diferentes conceitos de participação, principalmente com discussões no campo da teoria da ciência política, a essência central de participação do indivíduo é a mesma. Gohn afirma que "participação é uma das palavras mais utilizadas no vocabulário político, científico e popular da modernidade" (Gohn, 2013, p. 14).

Percebe-se que existem diferentes tipos de conceito de participação, discussões no campo da teoria da ciência política, o que não será abordado nesta pesquisa, uma vez que se deseja avaliar participação no sentido de manifestação do indivíduo e quais as oportunidades ou espaços abertos para essa manifestação no campo da avaliação de impacto ambiental. A resposta de Arnstein em 1969 para a definição de participação seria a "constatação de que participação cidadã constitui um sinônimo para poder cidadão" (Arnstein, 1969, p. 216).

Os méritos da participação pública nas tomadas de decisões incluem: atender à necessidade de diversas culturas, utilizar o conhecimento leigo e local, examinar o conhecimento especializado, legitimar os resultados dos processos de tomada de decisão, democratizar a tomada de decisão, aprendizado social, orientar o público, incorporar valores locais, construir confiança e reduzir custos de atrasos e de conflitos. A participação pode trazer inúmeros benefícios à sociedade e aos tomadores de decisão nos processos de AIA, mas também produz desafios, como a definição de atores, a escolha dos representantes e a informação suficiente de ambos os grupos, além de atender à exigência da manutenção de cronogramas compactos. Paralelamente aos desafios técnicos acima mencionados, a participação pública também comporta riscos éticos, tais como manipulações, obscurecendo discordâncias e fingindo uma democracia (Negev et al., 2013; Webler et al., 1995).

O papel da participação pública na avaliação de impacto ambiental sofreu uma grande mudança nos últimos anos. Nos primeiros dias da AIA, as principais formas de participação eram as audiências públicas e outros tipos de consulta, nas quais os gestores públicos ou tomadores de decisão podiam obter informações sobre as preocupações e orientações ao público sobre os projetos propostos, sendo que a ênfase ficava a cargo da troca de informações entre o saber local e as informações apresentadas em um relatório. A visão emergente do processo de AIA sustenta que a participação não é apenas uma parte suplementar da avaliação, mas um processo coletivo onde diferentes atores - cidadãos, grupos de interesse, autoridades e especialistas - podem deliberar e trocar suas opiniões sobre os objetivos e seus conhecimentos a respeito dos impactos dos projetos de desenvolvimento propostos (Saarikoski, 2000).

A preocupação com o envolvimento da sociedade na AIA teve um despertar teórico na década de 1990, influenciado pelos novos pensamentos 
conceituais de democracia participativa e justiça ambiental, incluindo grupos e indivíduos em uma comunidade, na sua forma mais ampla de envolvimento, ao contrário do modelo racionalista de tomada de decisão que vinha sendo aplicado nos processos de AIA desde a década de 1970. Essa tendência foi reforçada quando a União Europeia alterou as suas Diretivas para a AIA e passou a incorporar os princípios da Convenção de Aarhus sobre o acesso à informação e participação pública no processo de tomada de decisão (Morgan, 2012).

Foi publicado em 2006, pela Associação Internacional de Avaliação de Impacto Ambiental, cuja sigla em inglês é IAIA ${ }^{3}$, um documento que traz os Princípios Internacionais de Melhores Práticas de Participação Pública, com o objetivo de promover práticas mais sérias de participação pública entre os profissionais de avaliação de impacto. Neste documento, a participação pública pode ser definida como o "envolvimento de indivíduos e grupos que são positivamente ou negativamente afetados por, ou que estão interessados em uma proposta de projeto, programa, plano ou política que está sujeita a um processo de decisão" (André et al., 2006).

As formas de participação pública na avaliação de impacto ambiental podem ser classificadas como: participação passiva ou recepção de informações (uma forma unidirecional), participação por meio de consultas (tais como audiências públicas e reuniões abertas), participação interativa (tais como workshops, negociação, mediação e cogestão) (André et al., 2006).

Em uma análise mais aprofundada dos níveis e formas de participação, a cientista política Pateman realiza uma definição semelhante à da IAIA, conforme a Tabela 1.
TABELA 1 - Níveis e formas de participação

\begin{tabular}{ll}
\hline \multirow{2}{*}{ Pseudoparticipação } & $\begin{array}{l}\text { Quando há somente uma consulta a } \\
\text { um assunto por parte das autoridades. } \\
\text { Exemplo: audiências públicas, consultas } \\
\text { públicas e reuniões abertas. }\end{array}$ \\
\hline Quando muitos atores tomam parte do \\
processo, mas só parte decide de fato.
\end{tabular}

FONTE: Elaborada por Faria com base em Gohn (2013).

Já O’Faircheallaigh (2010) sugere três níveis de classificação de participação pública no processo de AIA: um nível no qual se obtém contribuições do público separadamente por tomadores de decisão, outro que se oferece algum grau de compartilhamento público no processo de tomada de decisão, e aquele em que a sociedade exerce realmente o poder de decisão, alterando as estruturas e as relações de poder decisório. Ele se esforça para evitar a noção de quadros estáticos ou modelos com limites rígidos, preferindo uma relação dinâmica entre as três formas de participação.

A transparência em relação às informações, o desconhecimento do público a respeito das questões de planejamento e licenciamento, assim como a incapacidade de influenciar no processo de tomada de decisão, aparecem como principais obstáculos à participação pública efetiva (Boyle, 1998; Li et al., 2012; Morgan, 2012).

A participação pública expõe ao longo do seu processo os saberes locais, a cultura, a política e o modo de vida da população, que são determinantes e importantes no processo de AIA e da tomada de decisão. A limitação do uso da internet nesse pro-

\footnotetext{
${ }^{3}$ Impact Assessment International Association.
} 
cesso como principal ferramenta de comunicação constitui desvantagem para as pessoas de áreas rurais com pouco ou nenhum acesso a esse meio. Para Morgan, precisa haver uma séria mudança cultural de todas as partes envolvidas, principalmente no que diz respeito à verdadeira importância da participação pública, fornecendo instrumentos e estrutura para a prática de forma eficaz desse direito (Morgan, 2012).

\subsection{Aspectos legais da participação pública na AIA no Brasil}

A participação pública no licenciamento ambiental no Brasil teve um tímido início em 1981, por meio do Decreto $n^{\circ} 88.351 / 1983$, que regulamenta a Política Nacional de Meio Ambiente (Brasil, 1981), quando, em seu artigo $1^{\circ}$, item VII, delegou a competência ao Poder Público de orientar a educação, em todos os níveis, para a "participação ativa do cidadão e da comunidade na defesa do meio ambiente, cuidando para que os currículos escolares das diversas matérias obrigatórias contemplem o estudo da ecologia" (Brasil, 1983, p. 1).

No mesmo Decreto, foi instituído que o Relatório de Impacto Ambiental seria acessível ao público e os pedidos de licenciamento seriam objeto de publicação em jornal oficial do Estado e em periódico de grande circulação regional ou local (Brasil, 1983).

No licenciamento ambiental submetido à avaliação por meio do EIA, quando a proposta de localização do projeto está na área de influência de terras indígenas ou quilombolas, o procedimento é a consulta formal aos órgãos oficiais que exercem a guarda dos interesses desses povos, como a Fundação Nacional do Índio (Funai) e a Fundação Cultural Palmares (FCP) (Brasil, 1967; 2015).

\subsubsection{Conselhos}

Os conselhos representam a possibilidade de participação pública de forma deliberativa, atualmente, na prática. Para Gohn (2013), "tratam-se de canais de participação que articulam representantes da população e membros do poder público estatal em práticas que dizem respeito à gestão de bens públicos" (Gohn, 2013, p. 7).

A Política Nacional de Meio Ambiente, que instituiu o Sistema Nacional de Meio Ambiente Sisnama, cria ainda o Conselho Nacional de Meio Ambiente - Conama - como órgão consultivo e deliberativo, com a finalidade de assessorar, estudar e propor ao Governo diretrizes de políticas governamentais para o meio ambiente e recursos naturais. Cabe ainda ao Conama deliberar no âmbito de sua competência sobre normas e padrões compatíveis com o meio ambiente ecologicamente equilibrado e essencial à qualidade de vida (Brasil, 1981).

Dentre as competências do Conama, está a de estabelecer, mediante proposta do Ibama, normas e critérios para o licenciamento de atividades efetiva ou potencialmente poluidoras, a ser concedido pelos Estados e supervisionado pelo Ibama (Brasil, 1981).

O Decreto Federal no 99.274/1990, que regulamenta a Lei Federal, instituiu a primeira composição do Conama, a frequência de reuniões e a atualização das competências do Conselho (Brasil, 1990). O Conselho Nacional de Meio Ambiente (Conama) é formado por 95 membros, sendo que a grande maioria do Conselho é formada por representantes do Governo, seja da esfera Federal, Estadual ou Municipal, seguida pela representação da Sociedade Civil e depois da classe empresária, conforme mostra a Figura 1. 


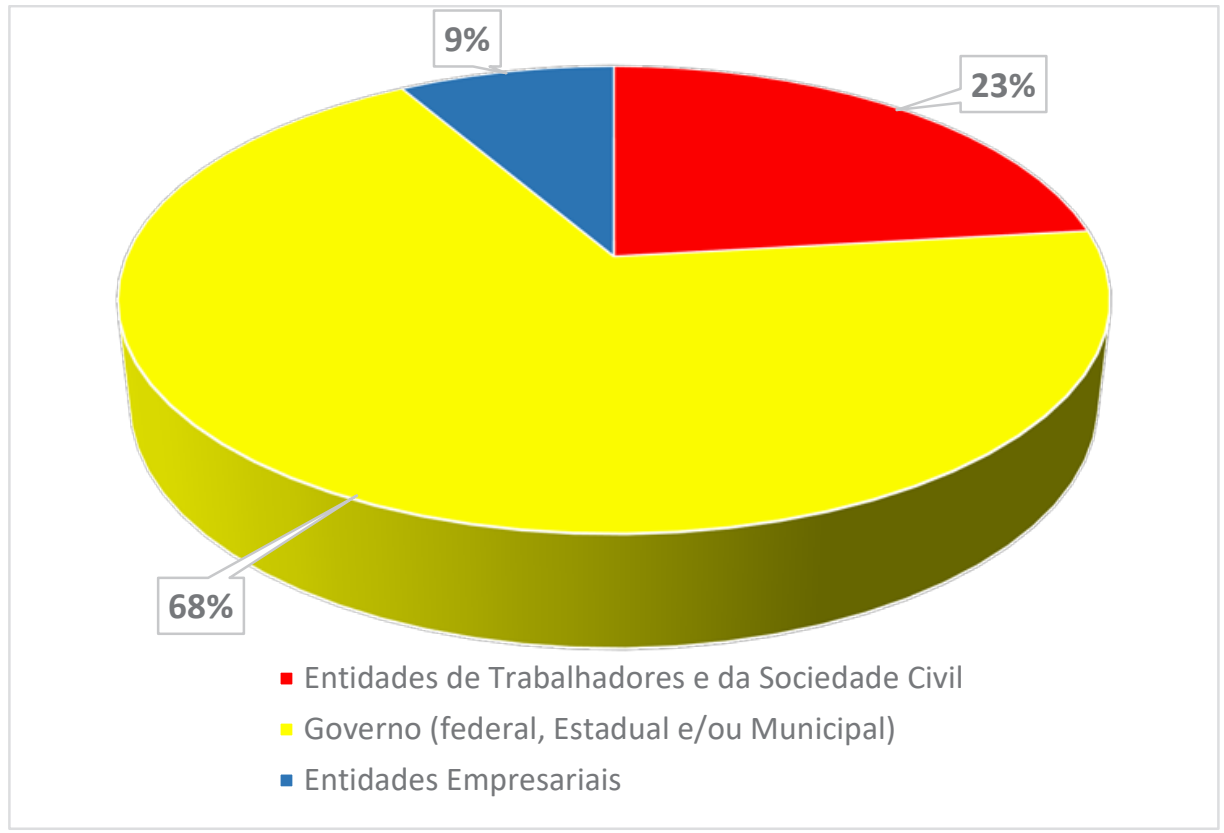

FIGURA 1 - Representação no CONAMA das entidades de trabalhadores, sociedades civil, empresariais, e governo.

FONTE: elaboração própria com base nos dados do site do Conama.

\subsubsection{Audiência pública}

As audiências públicas são fóruns abertos a qualquer indivíduo que deseja participar, geralmente acontecem em locais próximos à área pretendida do projeto ou empreendimento e são coordenadas pela autoridade ambiental nos processos de licenciamento (Negev et al., 2013).

Nestes fóruns abertos, os peritos ou técnicos apresentam seu conhecimento, podendo distanciar ainda mais o público dos processos de tomadas de decisões. Isso ocorre principalmente pelo fato de especialistas tenderem a utilizar expressões muito técnicas e de difícil entendimento para o cidadão comum. Dessa forma, pode-se afirmar que esses fóruns são muitas vezes concebidos para direcionar o público, em vez de oferecer oportunidades reais de participação no processo e na implementação de resultados na tomada de decisão (Negev et al., 2013).

A realização de audiência pública no processo de AIA pode ser solicitada por entidade civil, Ministério Público ou pelos cidadãos à autoridade ambiental, conforme determina a Resolução Conama $n^{\circ}$ 09/87. Conforme seu Art. $3^{\circ}$, a audiência deverá ser dirigida pelo representante do órgão licenciador que, "após exposição objetiva do projeto e do seu respectivo Rima, abrirá as discussões com os interessados" (Conama, 1987).

Embora seja um instrumento amplamente utilizado no processo de AIA, termos como quando couber ou quando julgar necessário $0^{4}$ podem oferecer dúvidas quanto à obrigatoriedade da realização

4 Destaque da autora em razão de as expressões serem utilizadas na legislação vigente. 
de audiência pública em todos os processos de AIA no Brasil. Em estados como Minas Gerais, por exemplo, a autoridade ambiental estadual não realiza audiência em todos os processos de AIA, apenas quando solicitada pela sociedade civil ou pelo Ministério Público (Almeida, 2013; Negev et al., 2013).

\section{Metodologia}

A metodologia utilizada para elaboração deste artigo classifica-se como exploratória e documental e envolveu a consulta de documentos que tramitam pelos processos administrativos do serviço público no âmbito do IEMA (Gil, 2010).

O IEMA é o órgão ambiental do Estado integrante do Sisnama na execução da Política Nacional de Meio Ambiente (PNMA) e responsável pelo licenciamento ambiental em todo o território estadual, para empreendimentos e/ou projetos cujos impactos não ultrapassem os limites do território do Espírito Santo.

Para se atingir o objetivo do artigo, foram considerados os processos de licenciamento ambiental que tiveram algum tipo de participação pública em sua fase de avaliação de impacto ambiental do projeto, a partir da publicação do Decreto $\mathrm{n}^{\circ}$ 1.777-R (2007), em vigor, no período pesquisado para efeitos de regulamentação do licenciamento ambiental no Estado, até maio de 2016. Dessa forma, todos os projetos que apresentaram EIA para seu licenciamento ambiental foram considerados na presente pesquisa.

\section{Resultados e discussão}

Foram identificados os instrumentos de participação pública que são praticados no processo de
AIA de projetos no Estado do Espírito Santo, no âmbito do IEMA, desde a publicação do Decreto Estadual $n^{\circ} 1.777-R$. A Tabela 2 apresenta os tipos de participação pública exercidos no Estado do Espírito Santo, conforme pesquisa documental realizada na autoridade licenciadora.

No Estado do Espírito Santo, existem atualmente cinco etapas do licenciamento ambiental que permitem a participação pública e a Tabela 3 apresenta os níveis de participação praticados no âmbito do IEMA e previstos na legislação em relação aos níveis de interação indicados na revisão da bibliografia.

Mediante publicação em jornal de grande circulação, é dada publicidade ao requerimento de licença, que será analisado pela autoridade ambiental. Este é o primeiro momento de participação pública ao longo do processo de licenciamento ambiental por meio da participação passiva, que é o tipo de participação pública mais utilizado no estado (André et al., 2006, p. 1). Pode-se afirmar que existiu participação pública em todos os 1.961 processos de licenciamento do período analisado, uma vez que é condição dada ao requerente da licença prévia dar publicidade à solicitação de licença ambiental junto ao IEMA. Esse tipo de participação é classificado como participação passiva ou recepção de informações, quando o cidadão não tem a oportunidade de interagir com o tomador de decisão, mas apenas recebe a informação.

O primeiro contato do tomador de decisão com o público ocorre na etapa de consulta prévia, que é anterior à elaboração do EIA. Trata-se da etapa de definição do escopo, uma das etapas iniciais da AIA, conforme afirma Sánchez (2013). As consultas são realizadas de forma similar às audiências públicas, onde membros da comunidade e autoridades da área de influência direta do projeto são convidados a participar. 
TABELA 2 - Estrutura da participação pública no Estado do Espírito Santo

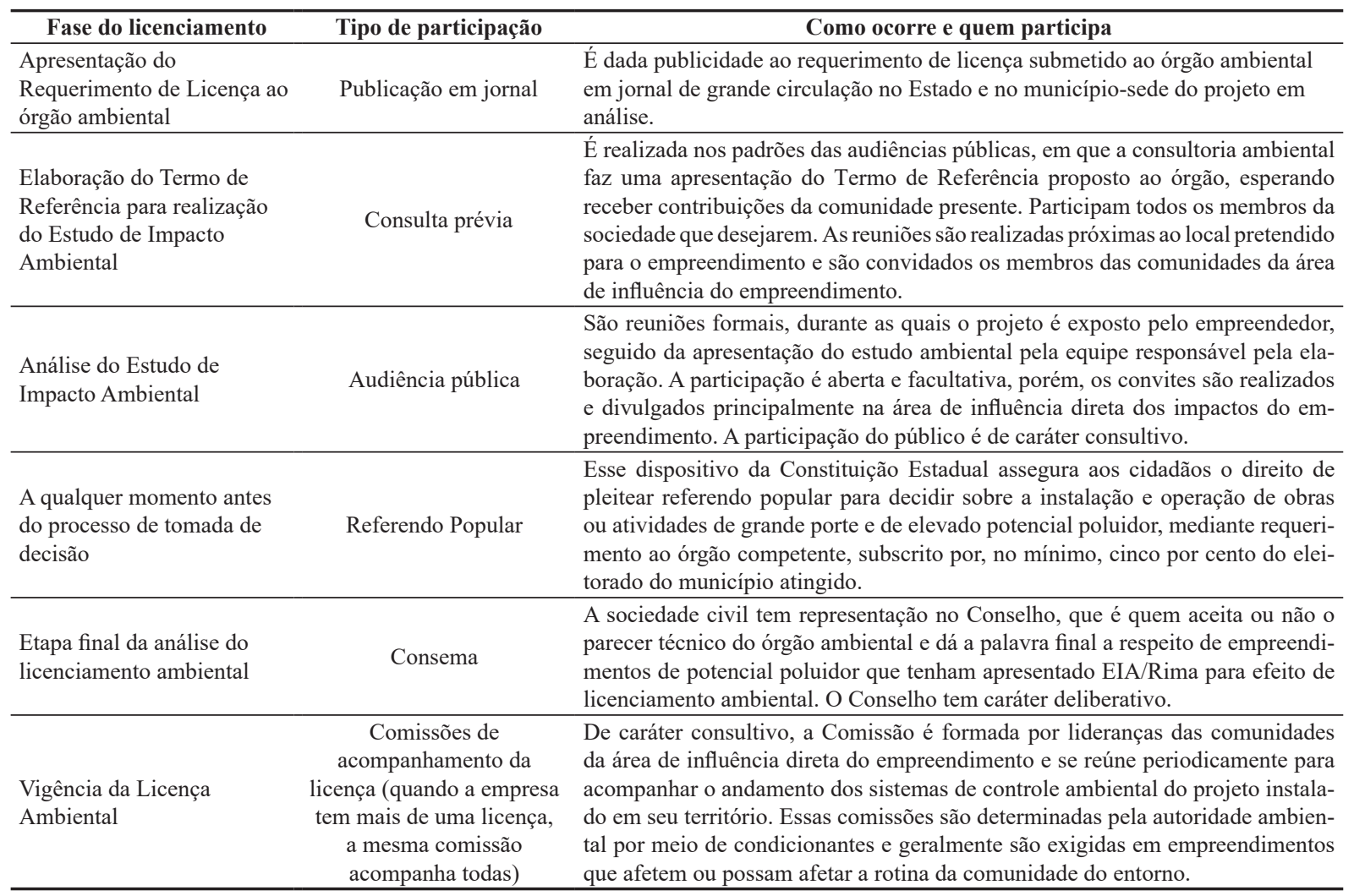

FONTE: Elaboração própria.

TABELA 3 - Níveis de participação pública identificados na prática e na legislação estadual vigente

\begin{tabular}{|c|c|c|}
\hline Níveis de participação pública & Praticados no âmbito do IEMA & $\begin{array}{c}\text { Previstos na legislação } \\
\text { estadual }\end{array}$ \\
\hline Participação passiva & $\begin{array}{l}\text { - Publicação do requerimento de licença } \\
\text { ambiental } \\
\text { - Publicação da concessão da licença ambiental }\end{array}$ & $\begin{array}{l}\text { - Publicação do requerimento de licença } \\
\text { ambiental } \\
\text { - Publicação do deferimento ou indeferimento } \\
\text { do requerimento de licença ambiental }\end{array}$ \\
\hline Participação por meio de consulta & $\begin{array}{ll}\text { - } & \text { Consulta prévia de termo de referência (TR) } \\
\text { - } & \text { Audiência pública } \\
\text { - } & \text { Comissões de acompanhamento }\end{array}$ & $\begin{array}{l}\text { - } \quad \text { Consulta prévia de TR } \\
\text { - } \quad \text { Audiência pública }\end{array}$ \\
\hline Participação interativa & - Conselhos & $\begin{array}{ll}\text { - } & \text { Conselhos } \\
\text { - } & \text { Referendo popular }\end{array}$ \\
\hline
\end{tabular}

FONTE: Elaboração própria com base em André e outros (2006). 
No período pesquisado, foram realizadas 18 reuniões consultas públicas para termo de referência de EIA em diversos municípios do estado, para 12 projetos em licenciamento. Os projetos que tiveram consulta pública para termo de referência são predominantemente da indústria de material de transporte, metalmecânica ou obras e estruturas diversas. Dos 21 processos de energia submetidos ao licenciamento, apenas 9,5\% tiveram consulta pública. Não foi realizada consulta pública para nenhum dos projetos de gerenciamento de resíduos licenciados no período pesquisado, ao contrário dos projetos de indústria metalmecânica e indústria de material de transporte, onde todos tiveram consulta pública em seu processo de licenciamento. Para os tipos de empreendimentos classificados em obras e estruturas diversas, a realização de consultas públicas foi de $58 \%$ em relação aos processos de licenciamento submetidos no período analisado.

Já a etapa em que ocorrem as audiências públicas é a fase de análise do estudo apresentado antes da tomada de decisão, etapa essa abordada por Sánchez (2013) na descrição das etapas da AIA. As audiências públicas são reuniões de caráter consultivo, onde é permitida a participação de qualquer membro da sociedade. São realizadas apresentações sobre o empreendimento e seus impactos, e posteriormente os presentes podem elaborar perguntas aos representantes da empresa, da consultoria ou mesmo do órgão ambiental responsável pelo licenciamento. De acordo com a documentação analisada, a autoridade ambiental do Estado do Espírito Santo realizou audiência pública para todos os processos de AIA de projetos que passaram por análise técnica. Dos 44 processos de licenciamento pesquisados, foram emitidas 27 licenças ambientais e realizadas audiências para 34 projetos.
A fase de tomada de decisão tem início quando a equipe de análise do EIA emite parecer técnico a favor da concessão da licença prévia ao projeto, e este parecer é encaminhado ao Conselho para apreciação em plenária. A última fase da tomada de decisão é a do Conselho, porém, cabe ressaltar que apenas os processos de licenciamento com parecer técnico positivo do IEMA para a concessão da licença são encaminhados ao Conselho. Ou seja, os processos de licenciamento onde o IEMA não concorda com o licenciamento não são apreciados pelo Conselho. Dessa forma, pode-se afirmar que a figura do tomador de decisão ${ }^{5}$ é exercida pela autoridade licenciadora e não pelo Conselho.

Durante a pesquisa documental realizada nas licenças ambientais emitidas nos projetos pesquisados, verificou-se a existência da participação pública após a emissão da licença ambiental pelas comissões de acompanhamento, que foram identificadas em oito projetos na etapa de acompanhamento do processo de AIA ou controle ambiental do projeto.

As comissões de acompanhamento são exigidas por meio de condicionantes ambientais que integram a licença ambiental de alguns empreendimentos e são compostas por representantes de associações de moradores indicadas no EIA, localizadas na área de abrangência dos impactos ambientais. Essas lideranças são convidadas a formar a comissão que acompanha, com participação em reuniões periódicas, toda a etapa de controle ambiental do projeto licenciado.

Em todas os documentos pesquisados nos processos de licenciamento ambiental objetos desta pesquisa, não foi identificada a realização de referendo popular ou mesmo qualquer solicitação formal para a realização.

\footnotetext{
${ }^{5}$ Nos casos de licenciamento ambiental no Espírito Santo, objeto de análise desta pesquisa.
} 
A participação pública no processo de elaboração do EIA foi identificada em apenas um processo de licenciamento, que foi o projeto de um estaleiro no município de Aracruz.

O Estado do Espírito Santo possui previsão legal para exercer todos os níveis de participação pública recomendados como melhores práticas internacionais, porém, o nível decisório só é praticado por meio da representatividade da sociedade civil nos conselhos, uma vez que não existem evidências da realização de referendo popular, pelo menos no período pesquisado.

\section{Conclusão}

Este artigo permitiu a identificação dos dispositivos de participação pública previstos na legislação estadual do Espírito Santo e os praticados pela autoridade licenciadora. A prática de participação pública aplicada ao licenciamento é superficial quando se analisa a proporção da realização de participação passiva em relação a outros tipos de participação com maior protagonismo da sociedade. No Estado do Espírito Santo, atualmente, existem na prática cinco etapas do licenciamento ambiental que permitem a participação pública: publicação do requerimento de licença ambiental, consulta prévia para termo de referência, audiência pública, Conselhos e comissões de acompanhamento da licença ambiental. Porém, o único instrumento de participação pública que poderia proporcionar um protagonismo verdadeiro no processo de tomada de decisão nunca foi aplicado. O Estado do Espírito Santo prevê em seu arcabouço legal iniciar o processo de participação pública consultiva antes da definição do escopo no processo de AIA, porém, essa ferramenta foi utilizada em 12 dos 44 processos Mesmo ainda incipientes, as comissões de acompanhamento de condicionantes representam uma oportunidade para a comunidade adquirir conhecimento e participar da etapa de controle ambiental no processo de AIA, sentindo-se parte do processo mesmo após a emissão da licença ambiental.

Ainda que com representação da sociedade civil, do ponto de vista de participação pública, os conselhos exercem uma função limitada no processo de AIA no Estado do Espírito Santo, tendo em vista que os processos de AIA em sua maioria não vêm a ser encaminhados àquela plenária.

Este trabalho representou conhecimento para o IEMA sobre o assunto abordado, e abriu a possibilidade de melhorar as ferramentas de participação pública nos processos de AIA no Estado do Espírito Santo, e talvez servindo de exemplo para outros estados do Brasil.

Existe ainda a possibilidade de melhorar e ampliar a participação pública na AIA por meio de ferramentas eletrônicas, como teleconferências, e-mails, fóruns eletrônicos ou mesmo consultas em sítios eletrônicos. A aplicação dessas técnicas de participação pública poderia solucionar problemas logísticos ou até mesmo de limitações conceituais, porém, os responsáveis pela aplicação dessas técnicas devem avaliar com cautela a eficácia desses instrumentos nos diversos tipos de público e a particularidade de cada projeto e sua região para fortalecer a democracia. 


\section{Referências}

Almeida, M. R. R. e. Aplicação da abordagem sistêmica para análise da efetividade da avaliação de impacto ambiental no Brasil: um estudo para os estados de São Paulo e Sul de Minas Gerais. 2013. 171 f. Tese (Doutorado em Engenharia Ambiental) - Programa de Pós-Graduação em Ciências da Engenharia Ambiental, Escola de Engenharia de São Carlos, Universidade de São Paulo, São Carlos, 2013.

André, P. B.; Enserink, B.; Connor, D.; Croal, P. Public participation international best practice principles. Fargo, USA: IAIA, 2006. (Special Publication Series no 4).

Arnstein, S. R. A ladder of citizen participation. Journal of the American Institute of Planners, 35(4), 216-224, 1969.

Becker, D. R.; Harris, C. C.; McLaughlin, W. J.; Nielsen, E. A. A participatory approach to social impact assessment: the interactive community forum. Environmental Impact Assessment Review, 23(3), 367-382, 2003.

Bond, A. J.; Pope, J.; Morrison-Saunders, A.; Retief, F.; Gunn, J. A. E. Impact assessment: eroding benefits through streamlining? Environmental Impact Assessment Review, United Kingdom, 45, 46-53, 2014.

Boyle, J. Cultural influences on implementing environmental impact assessment: insights from Thailand, Indonesia, and Malaysia. Environmental Impact Assessment Review, 18(2), 95-116, 1998.

Brasil. Lei Ordinária no 5.371, de 05 de dezembro de 1967. Autoriza a instituição da Fundação Nacional do Índio e dá outras providências. Diário Oficial [da] República Federativa do Brasil, Brasília, 6 dez. 1967. Disponível em: <http:// www.planalto.gov.br/ccivil_03/Leis/1950-1969/L5371. $\mathrm{htm}>$. Acesso em: 12 jul. 2015.

Brasil. Lei Complementar no 6.938, de 31 de agosto de 1981. Dispõe sobre a Política Nacional do Meio Ambiente, seus fins e mecanismos de formulação e aplicação, e dá outras providências. Diário Oficial [da] República Federativa do Brasil, Brasília, 2 set. 1981.

Brasil. Decreto $n^{\circ} 88.351$, de $1^{\circ}$ de junho de 1983. Regulamenta a Lei $\mathrm{n}^{\circ} 6.938$, de 31 de agosto de 1981, e a Lei $\mathrm{n}^{\circ}$ 6.902, de 27 de abril de 1981, que dispõem, respectivamente, sobre a Política Nacional do Meio Ambiente e sobre a criação de Estações Ecológicas e Áreas de Proteção Ambiental, e dá outras providências. Diário Oficial [da] República Federativa do Brasil, Brasília, 9 dez. 1983.

Brasil. Constituição (1988). Constituição [da] República Federativa do Brasil. Brasília, DF: Senado Federal, 1988.

Brasil. Decreto ${ }^{\circ}$ 99.274, de 6 de junho de 1990. Regulamenta a Lei ${ }^{\circ}{ }^{6} .902$, de 27 de abril de 1981, e a Lei n ${ }^{\circ} 6.938$, de 31 de agosto de 1981, que dispõem, respectivamente, sobre a Política Nacional do Meio Ambiente e sobre a criação de Estações Ecológicas e Áreas de Proteção Ambiental, e dá outras providências. Diário Oficial [da] República Federativa do Brasil, Brasília, 7 jun. 1990. Disponível em: $<$ http://www.planalto.gov.br/ccivil_03/decreto/antigos/ d99274.htm>. Acesso em: 12 jul. 2015.

Brasil. Ministério da Cultura. Fundação Cultural Palmares. Sistemática do processo de licenciamento ambiental com envolvimento da FCP/MINC: fluxo e procedimentos. Brasília, 2015. Disponível em: $<$ http://www.palmares.gov. br/wp-content/uploads/2015/03/FLUXOGRAMA-LICENCIAMENTO-AMBIENTAL-VFINAL.pdf>. Acesso em: 12 jul. 2015.

Cashmore, M. The role of science in environmental impact assessment: process and procedure versus purpose in the development of theory. Environmental Impact Assessment Review, 24(4), 403-426, 2004.

Conselho Nacional do Meio Ambiente (Brasil). Resolução Conama $n^{\circ} 1$, de 23 de fevereiro de 1986. Dispõe sobre critérios básicos e diretrizes gerais para avaliação de impacto ambiental. Diário Oficial [da] República Federativa do Brasil, Brasília, 17 fev. 1986. Seção 1, p. 2548-2549.

Conselho Nacional do Meio Ambiente (Brasil). Resolução Conama $n^{\circ}$ 9, de 3 de dezembro de 1987. Dispõe sobre a realização de audiências públicas no processo de licenciamento ambiental. Diário Oficial [da] República Federativa do Brasil, Brasília, 5 jul. 1990. Seção 1, p. 12945.

Espírito Santo (Estado). Lei $\mathrm{n}^{\circ} 3.582$, de 3 de novembro de 1983. Dispõe sobre medidas de proteção, conservação e melhoria do meio ambiente no estado do Espírito Santo. Diário Oficial [do] Estado do Espírito Santo. Vitória, 1983.

Espírito Santo (Estado). Lei no 4.126, de 22 de julho de 1988. Dispõe sobre a implantação da política estadual de 
proteção, conservação e melhoria do meio ambiente. Diário Oficial [do] Estado do Espírito Santo, Vitória, 25 jul. 1988.

Espírito Santo (Estado). Constituição (1989). Constituição [do] Estado do Espírito Santo. Vitória: Assembleia Legislativa, 1989.

Espírito Santo (Estado). Lei no 5.355 de 27 de dezembro de 1996. Institui o Cadastro Estadual de Entidades Ambientalistas do Estado do Espírito Santo. Diário Oficial [do] Estado do Espírito Santo. Vitória, 1996.

Espírito Santo (Estado). Decreto ${ }^{\circ}$ 4.344-N, de 7 de outubro de 1998. Regulamenta o sistema de licenciamento de atividades poluidoras ou degradadoras do meio ambiente. Diário Oficial [do] Estado do Espírito Santo. Vitória, 1998.

Espírito Santo (Estado). Decreto $\mathrm{n}^{\circ} 1.777-\mathrm{R}$, de 8 de janeiro de 2007. Dispõe sobre o sistema de licenciamento e controle das atividades poluidoras ou degradadoras do meio ambiente. Diário Oficial [do] Estado do Espírito Santo. Vitória, 2007.

Espírito Santo (Estado). Secretaria de Estado de Meio Ambiente e Recursos Hídricos. Portaria no 05-R, de 14 de abril de 2008. Vitória, 2008a. Disponível em: <www.oads. org.br/leis/3228.pdf>. Acesso em: nov. 2016.

Espírito Santo (Estado). Lei $\mathrm{n}^{\circ}$ 8.956, de 29 de julho de 2008. Altera dispositivos da Lei ${ }^{0} 5.355$, de 27.12.1996, que instituiu o Cadastro Estadual de Entidades Ambientalistas do Estado do Espírito Santo. Diário Oficial [do] Estado do Espírito Santo. Vitória, 2008.

Espírito Santo (Estado). Decreto no 4.344-N, de 7 de outubro de 1998. Regulamenta o sistema de licenciamento de atividades poluidoras ou degradadoras do meio ambiente. Diário Oficial [do] Estado do Espírito Santo. Vitória, 1998. Disponível em: <http://www.ciflorestas.com.br/arquivos/ lei_decreto_4.344n1998_13985.pdf>. Acesso em: $20 \mathrm{dez}$. 2016.
Gil, A. C. Como elaborar projetos de pesquisa. 5. ed. São Paulo: Atlas, 2010.

Glucker, A. N.; Driessen, P. P. J.; Kolhoff, A.; Runhaar, H. A. C. Public participation in environmental impact assessment: why, who and how? Environmental Impact Assessment Review, 43, 104-111, 2013.

Gohn, M. G. Conselhos gestores e participação sociopolitica. 4. ed. São Paulo: Cortez, 2013.

Li, W.; Liu, J.; Li, D. Getting their voices heard: three cases of public participation in environmental protection in China. Journal of Environmental Management, 98, 6572, may 2012.

Morgan, R. K. Environmental impact assessment: the state of the art. Impact Assessment and Project Appraisal, 30(1), p. 5-14, 2012.

Negev, M.; Davidovitch, N.; Garb, Y.; Tal, A. Stakeholder participation in health impact assessment: a multicultural approach. Environmental Impact Assessment Review, 43, 112-120, 2013.

O'Faircheallaigh, C. Public participation and environmental impact assessment: purposes, implications, and lessons for public policy making. Environmental Impact Assessment Review, 30, 19-27, 2010.

Saarikoski, H. Environmental impact assessment (EIA) as collaborative learning process. Environmental Impact Assessment Review, 20(6), 681-700, 2000.

Sánchez, L. H. Avaliação de impacto ambiental: conceitos e métodos. 2. ed. São Paulo: Oficina de Textos, 2013.

Webler, T.; Kastenholz, H.; Renn, O. Public participation in impact assessment: a social learning perspective. Environmental Impact Assessment Review, 15(5), 443-463, set. 1995. 